\title{
Beiträge zur Kenntniss der Helophoren aus Europa und den angrenzenden Ländern.
}

Von A. Kuwert in Wernsdorf (Ostpreussen).

(Fortsetzung.)*)

\section{Helophorus Mesopotamiae n. sp.}

Tichohelophorus, nubilo simillimus, sed minor, tarsis multo tenuioribus; ovato-oblongus, subtus testaceus, capite nigro, prothorace elytrisque fusco-testaceis, his plusminus nigro-testaceoque maculatis.

Capite plano, rugoso, cum oculis rotundato; sulco frontali furcato leniter inscripto. Prothorace rugoso, antice supra oculos utrinque exciso, angulis anterioribus vix in oculos et minus prominulis, quam apud "nubilum" speciem prominent; lateribus paene rectis antice paullo dilatatis, ante angulos autem posteriores ita excisis, ut anguli sint recti; sulco medio in medio non dilatato; sulcis internis in medio breviter et leniter sinuatis. Elytris brunneis vel fusco-testaceis, maculis nigris testaceisque plusminus tessellatis, striato-punctatis; striola punctata abbreviata apud scutellum; interstitiis alternatis carinatis; carinis serie setarum in apice retrocurvatarum ornatis; elytris duplo longioribus quam latis, post medium paullo dilatatis posticeque angustatis. Pedibus fusco-testaceis, anteriorum pedum tarsis mediis brevissimis, tarsis omnibus tenuibus. Palpis testaceis; ultimo articulo fusiformi. Long. $2 \mathrm{~mm}$.

Habitat in Asia minore ad fluvium Euphratem, etiam propè mare caspicum.

Diese viel kleinere Art als nubilus $\mathrm{F}$. unterscheidet sich von derselben hauptsächlich durch die schwächeren Tarsen, die geraden Seiten des Halsschildes und die nicht so weit vorgezogenen Vorderecken desselben. Nach der Motschulskischen Beschreibung des meridionalis Parreyss in litt. zu schliessen, ist dieses Thier nicht synonym mit dem vorstehend beschriebenen, sondern es ist in dem meridionalis Parreyss die südliche Variation von nubilus $\mathrm{zu}$ suchen.

\section{Helophorus Sahlbergi n. sp.}

Rhopalohelophorus, granulari simillimus, sed ultimo articulo palporum labialium longissime barbato, abdominis segmentis postice non pilosis, interstitiis elytrorum convexis serie punctorum impressis, tibiis non filis longis ornatis, elytrorum limbo posteriore crinito.

Capite metallico, mugoso; clypeo convexo; sulco frontali antrorsum dilatato et ibi paene arato. Prothorace metallescente, in

*) Siehe Jahrgang 1885 , pag. 312 . 
parte externo aureo-micante, in medio vix, sed in partibus exterioribus valde rugoso, antice paullo dilatato; marginibus paene rectis; sulco medio in medio paullo dilatato; sulcis internis in medio leviter externe arcuatis; sulcis externis rectis margini prothoracis non parallelis anticeque remotis. Elytris brunneis, metallescentibus, fortiter punctato-striatis; interstitiis convexis serie punctorum singulorum impressis, communi macula suturali, praeterea in sexto interstitio intra maculam suturalem marginemque externam utrinque puncto nigro maculatis, limbo posteriore crinitis, abdomen postice valde superantibus vixque post medium dilatatis. Pedibus testaceis; femoribus infuscatis; ultimo tarsorum infuscato articulo trium anteriorum tarsorum aequali longitudine. Palporum ultimo articulo semi-infuscato. Corpore subtus nigro-brunneo, vix tegumine tecto, abdomine pallidiore. Long. $2 \cdot 0 \mathrm{~mm}$.

Habitat in Sibiria.

Die lange Behaarung des letzten Lippentastergliedes, welche schnurbartähnlich vor die Mundtheile tritt und die Behaarung derselben Theile bei granularis um die doppelte Länge übertrifft, die Punktirung der gewölbten Interstitien und die Behaarung des äusseren, hinteren Flügeldeckenrandes heben diese Art reichlich von granularis ab.

Ich erhielt unter anderen bestimmten Helophoren aus Sibirien auch diese unbestimmte Art durch Herrn Dr. Sahl$\mathrm{b}$ erg in Helsingfors.

\section{Ueber Helophorus villosus Duftsch.}

Hel. villosus Duftsch. ist von dem Autor sehr kenntlich oder doch wenigstens so kenntlich in den ersten Jahren dieses Jahrhunderts beschrieben, dass derselbe nachher bei der grossen Exploration der Insectenwelt, zumal der Käfer, hätte wiedergefunden werden müssen. Dies ist anscheinend nicht der Fall. In keiner einzigen der beträchtlichen Helophorus-Sammlungen, welche a uf meinem Arbeitstische vorliegen, finde ich das Thier; kein Museum, das ich befragte, kein Sammler kann Auskunft geben. Selbst Redtenbacher, der seiner Tabelle die Duftschmidt'sche Beschreibung einverleibte, kannte das Thier nicht, das in Oesterreich zu Hause sein soll.

Es bleibt kaum etwas Anderes übrig, als die Existenz des Thieres in Frage zu ziehen, zumal die $\mathrm{Duftschmidt-}$ sche Beschreibung, wenn man von der Grösse des Käfers abstrahirt, so genau auf arvernicus Muls. passt, dass ich lange 
in Zweifel war, ob ich in einem sehr grossen Stücke von arvernicus in meiner Sammlung nicht das vermisste Thier vor mir hätte. Es hat dieses Stück nicht nur (bei einer allerdings șehr starken Vergrösserung) zwischen den Punktstreifen auf den Intervallen feine kurze Härchen, sondern es werden dieselben auf dem hinteren Flügelende sogar warzenartig stark. Wenn, was ich wünsche, diese Veröffentlichung einen wirklichen villosus Duftsch, an das Tageslicht führen sollte, würde ich mich gerne eines Besseren bescheiden. Im entgegengesetzten Falle würde auch dieses Thier zu cassiren sein, weil $\mathrm{Duft}$ schmidt dann wohl nur ein exorbitant grosses Stück von arvernicus vor sich gehabt haben dürfte oder ein zufällig des abgekürzten Punktstreifens entbehrendes Stück von villosus Küst., auf welchen Käfer die Beschreibung allerdings nicht so gut passt.

\section{Helophorus aquaticus L., villosus Küst. und var. Milleri m.}

Durch Herrn Miller in Wien ging mir eine Reihe von Stücken des aquaticus zu, welche sich durch eine ziemlich starke Behaarung der Flügeldecken auszeichnen, die auf sämmtlichen Flügeldeckenintervallen sich zeigt, aus ziemlich anliegenden, rückwärtsgebogenen Härchen besteht und mit einzelnen langen Haaren durchsetzt ist. Da auffallenderweise die Männchen bei diesen Thieren ebenso gross sind, als die Weibchen, was bei aquaticus $\mathrm{L}$. bekanntlich nicht der Fall ist, so wird diese dem Süden angehörende und, wie es scheint, in Corfu besonders entwickelte Varietät, welche identisch ist

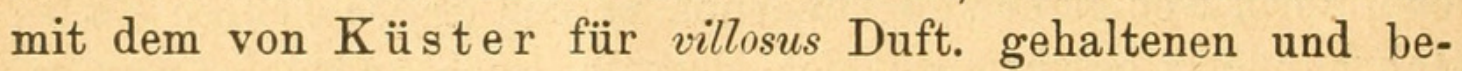
schriebenen Thiere, um Irrungen vorzubeugen, besonders zu benennen sein, und habe ich hierfür den Namen Milleri gewählt. Das Thier ist fast durchwegs mit helleren Flügeldecken als die nordische Art und hat meistens stark goldigen Kopf und Halsschild. Das letzte Tarsenglied, welches bei den kleineren Männchen von aquaticus an seinem Ende stets schwarz ist, bleibt bei Var. Milleri gleich den ganzen Beinen rothgelb, wie überhaupt bei ihr Männchen und Weibchen gleich oder ziemlich gleich gefärbt sind, während bei aquaticus die Männchen im Durchschnitt dunkler sind. Der Halsschild ist vorne und an den Seiten meistens gelb gerandet, sämmtliche $\mathrm{Z}_{\text {wischenräume }}$ der Flügeldecken etwas mehr gewölbt, als bei der Stammform. 


\section{$2 \mathrm{BHL}$ Biodiversity Heritage Library}

Kuwert, August Ferdinand. 1886. "Beiträge zur Kenntniss der Helophoren aus Europa und den angrenzenden Ländern. Fortsetzung." Wiener entomologische Zeitung 5, 90-92. https://doi.org/10.5962/bhl.part.20562.

View This Item Online: https://www.biodiversitylibrary.org/item/43771

DOI: https://doi.org/10.5962/bhl.part.20562

Permalink: https://www.biodiversitylibrary.org/partpdf/20562

\section{Holding Institution}

Smithsonian Libraries

\section{Sponsored by}

Smithsonian

\section{Copyright \& Reuse}

Copyright Status: NOT_IN_COPYRIGHT

This document was created from content at the Biodiversity Heritage Library, the world's largest open access digital library for biodiversity literature and archives. Visit BHL at https://www.biodiversitylibrary.org. 